1 Williams JGK, Kubelik AR, Livak KJ, Rafalsk JA, Tingey SV. DNA polymorphism amplified by arbitrary primers are useful genetic markers. Nucleic Acids Res. 1990;18: 6531-5.

2 Welsh J, McClelland M. Fingerprinting genomes using PCR with arbitrary primers. Nucleic Acids Res. 1990;18: 7213-8.

3 Caetano-Anollés G, Bassam BJ, Gresshoff PM. DNA amplification fingerprinting using very short arbitrary oligonucleotide primers. Biotechnology 1991;9:553-7.

4 Pitcher DG, Saunders NA, Owen RJ. Rapid extraction of bacterial genomic DNA with guanidium thiocyanate. Letters in Applied Microbiology. 1989;8:151-6.

5 Jayarao BM, Bassam BJ, Caetano-Anollés G, Gresshof Jayarao BM, Bassam BJ, Caetano-Anolles G, Gresshof
PM, Oliver SP. Subtyping of Streptococcus uberis by PM, Oliver SP. Subtyping of Streptococcus uberis by 1992;30:1347-50.

\section{Direct culture of gonococci in the patient care area}

Suspected gonococcal cervicitis or urethritis is usually confirmed by culture. Direct culture onto a selective medium in the patient care area followed by immediate incubation of the plates at the right atmosphere is considered to be the most sensitive method in the diagnosis of gonococcal infections. ${ }^{1}$ If direct plating is not possible, the samples may be either transported in nonnutritive holding media such as Stuart or Amies medium, or in nutritive transport systems. We tested the ability of a commercial nutritive transport system, Biocult-CCR (Orion Diagnostica, Espoo, Finland) to support the survival and growth of gonococci.

The urethral and cervical samples were taken at the Department of Sexually Transmitted Diseases (STD), Aurora Hospital, Helsinki, by two STD specialists, and inoculated directly at the patient's side first onto a modified Thayer-Martin (TM) medium (BBL GCII) agar base with $1.7 \%$ of haemin, $5 \%$ chocolated horse blood, $1 \%$ IsoVitalex, vancomysin $1 \mathrm{mg} / \mathrm{l}$, mycostatin $50 \times$ $10^{5} \mathrm{IU} / 1$, colimycin $0.6 \mathrm{mg} / \mathrm{l}$, trimethoprim 2 $\mathrm{mg} / \mathrm{l}$ and clindamycin $0.2 \mathrm{mg} / \mathrm{l}$ ) and next, using the same swab, onto the agar surfaces of the Biocult-GC transport system. The TM plates were immediately placed in a $35^{\circ} \mathrm{C}$ incubator in a humidified atmosphere of $5 \%$ $\mathrm{CO} 2$ in air. The Biocult-GC transport device was transferred into its container, $\mathrm{CO} 2$ generating tablet added, the container closed tightly and placed at $35^{\circ} \mathrm{C}$. The $\mathrm{TM}$ plates were transferred to the microbiology laboratory on the next floor the following morning, and Biocult-GC transported to another microbiology laboratory after 15 to $48 \mathrm{~h}$ incubation at the STD Department. The TM plates and Biocult-GC were examined for growth of gonococci after 48 hours of culture by two independent microbiologists. $N$ gonorrhoeae growing on TM plates were identified by colony morphology, Gram stain, positive oxidase test, agglutination by monoclonal antibody (Phadebact Monoclonal GC Test 50, KaroBio Diagnostics Ab, Huddinge, Sweden), and production of acid from glucose but not from maltose or lactose. The sensitivity to penicillin (by E-test ${ }^{\mathrm{R}}$, Biotest, Stockholm, Sweden) and ciprofloxacin (by disc diffusion test, Rosco, Taastrup, Denmark) as well as beta-lactamase production were also determined. $N$ gonorrhoeae on Biocult-GC were likewise identified by colony morphology, Gram stain, oxidase positivity and growth characteristics.

First, 199 consecutive samples were studied. Smears of four patients revealed intracellular diplococci in methylene blue staining. Growth of $N$ gonorrhoeae was detected in three samples $(1.5 \%)$ on TM plates and on Biocult-GC (Table, group 1). One of the samples grew only on TM plates, another on Biocult-GC only.

In the second part of the study, samples from patients with clinically suspected $N$ gonorrhoeae infection and from two patients not suspected to have gonococcal infection but visiting the STD Department on the same day as the index patient were studied. Intracellular diplococci were found in 33 smears from the 102 patients. $N$ gonorrhoeae was detected by culture in 33 samples from 30 patients. Cultures from 29 patients were positive on TM plates and from 26 on Biocult-GC (Table 1, group II). Biocult-GC failed to show growth of $N$ gonorrhoeae in samples of four patients growing on TM and TM from one growing on Biocult-GC. The difference between the yields on $T M$ and Biocult-GC was statistically not signficant.

Although the overall agreement between TM and Biocult-GC cultures was good, five samples failed to grow on Biocult-GC and two on TM. This result may be biased as Biocult-GC was always inoculated after the TM plate (but using the same swab for both), and might have had a smaller inoculum than TM.

Gonococci are fastidious organisms and may survive in nonnutritive transport tubes for less than 24 hours. ${ }^{1}$ In this study BiocultGC supported the survival and growth of $N$ gonorrhoeae to the same extent as direct plating onto TM plates in the patient care area and may thus be an alternative to nonnutritive transport tubes if direct inoculation of samples onto TM plates in the patient care area is not possible, but inoculation, incubation and safe transport of cultured Biocult GC is. Presumptive identification of

Table Detection of $N$. gonorrhoeae on Thayer-Martin (TM) plates and Biocult-GCR

\begin{tabular}{lllccc}
\hline \multirow{2}{*}{ Group } & \multicolumn{5}{l}{ Growth of gonococci } \\
\cline { 3 - 6 } & $n$ & $T M$ & Biocult-GC & Total & $p^{+}$ \\
\hline I & $199(153)^{\star}$ & $3(3)$ & $3(3)$ & $4(4)$ & 0 \\
II & $131(102)$ & $31(29)$ & $28(26)$ & $33(30)$ & $0 \cdot 1969$ \\
AII & $330(255)$ & $34(32)$ & $31(29)$ & $37(34)$ & $0 \cdot 1536$ \\
\hline
\end{tabular}

$66 \%(102)$ of the patients were females in group 1 , and $43 \%$ (43) in group II.

* Number of samples (patients) studied.

†Yield on Thayer-Martin plates and Biocult-GC compared by Chi square test; all p-values not significant. 
$N$ gonorrhoeae (by colony morphology, Gram stain, oxidase positivity, and agglutination by monoclonal antibody) would be available from both Biocult-GC and TM plates inoculated at patient care area in 24 to 48 hours, and final results with antibiotic sensitivity 24 hours later. Savings in labour costs and culture materials may also be achieved as only Biocult-GC and TM plates with colonies suspected to be $N$ gonorrhoeae need to be further studied and cultured at the microbiological laboratories. It has to be emphasised, however, that our results were obtained in a department where the samples were taken by STD specialists, and in a department which is supported by a medical microbiology laboratory next door. A comparison between Biocult-GC nutritive transport system and nonnutritive transport media should be performed in primary health care centres in order to test the survival of gonococci in the two systems. Medical Microbiology, Aurora Hospital, Nordenskiöldinkatu 20 $S F 00250$ Helsinki, Finland
E HILTUNEN-BACK Department of Sexually Transmitted Diseases, Aurora Hospital, Nordenskiöldinkatu 20 SF 00250 Helsinki, Finland L SCHEININ

Department of Research and Development, Orion Corporation Orion Diagnostica,

Address correspondence to: Dr S Kontiainen Espoo, Finland

1 Morello JA, Janda WM, Doern CV. Neisseria and Branhamella. In: Manual of Clinical Microbiology, 5th ed. Balows A, Hausler WJ, Herrmann KL, Isenberg HD,
Shadomy HJ eds. Washington DC American Society for Microbiology, 1992, 258-76.

Accepted for publication 3 May 1993

\section{Hepatitis $B$ infection post Engerix B} vaccination

We report a case of documented hepatitis $B$ virus (HBV) infection despite active immunisation with Engerix $B$ vaccine and positive hepatitis B surface antibody (anti-HBs).

A 21 year old homosexual man was first diagnosed to be HIV antibody positive in January 1991. He remains asymptomatic. His latest T helper cell count in January 1993 was $0.42 \times 10^{9} / 1$. Hepatitis serology in January 1991 showed negative hepatitis B surface antigen (HBsAg) and negative hepatitis B core antibody (anti-HBc), both performed with radioimmunoassay (RIA).

Three doses of $20 \mu \mathrm{g}(1 \mathrm{ml})$ of Engerix B (Smith Kleine French) hepatitis $B$ vaccine were given by deep intramuscular injection in March, May and October of 1991. Three months later he still showed negative HBsAg, antiHBc and anti HBs (measured by enhanced luminescent assay). A fourth dose of Engerix B was given in April 1992. Two months later he showed negative $\mathrm{HBsAg}$, negative anti-HBc, but weakly positive anti$\mathrm{HBs}$, with a titre of only $14 \mathrm{mIU} / \mathrm{ml}$. A further dose of vaccination was therefore recommended.

However, the patient defaulted follow-up for the next six months and returned in January 1993 for a routine check-up. The fifth dose of Energix B vaccine was then given.

Repeat hepatitis serology two weeks later showed positive $\mathrm{HBsAg}$, positive anti-HBc, positive $\mathrm{HBeAg}$, negative anti-HBs, negative anti-HBe and negative anti-HBc IgM. His asparate amino transferase (AST) level was elevated to $290 \mathrm{U} / 1(5-35 \mathrm{U} / \mathrm{l})$. Nine days later he had negative $\mathrm{HBsAg}$, positive anti$\mathrm{HBc}$ IgM, negative $\mathrm{HBeAg}$ and positive anti$\mathrm{HBe}$. His AST was 91U/1. He remained totally asymptomatic during this period, and had a normal serum bilirubin level (11 $\mu \mathrm{mol} / \mathrm{l})$. These results indicate that he had a subclinical hepatitis B infection (table). He admitted to unprotected penetrative sexual intercourse with his regular partner, whose HIV and hepatitis status is not known. He is not known to be an intravenous drug user or have any other risk factors for hepatitis B infection.

This case illustrates several interesting points. Firstly, the time required for effective hepatitis immunisation can be quite protracted, especially in the initial non-responders. Patients can therefore become infected with hepatitis $B$ virus during the process of immunisation.

Secondly, anti-HBs level of $14 \mathrm{miu} / \mathrm{ml}$ failed to protect this patient from hepatitis $B$ infection, although it may have served to protect him against clinical disease and against becoming a chronic carrier. $\mathrm{HBV}$ infection events are known to occur in subjects who are either poor or non-responders to vaccine. ${ }^{12}$ The highest anti-HBs titre described which failed to protect against $\mathrm{HBV}$ infection was 23 samples to ratio units, which are equivalent to our $\mathrm{miu} / \mathrm{ml}^{1}{ }^{1}$ In our laboratory, we consider anti-HBs level below $100 \mathrm{miu} / \mathrm{ml}$ as poor responders and recommended booster doses for these patients.

Thirdly, this patient's hepatitis infection was detected through a laboratory screening programme which included $\mathrm{HBsAg}$ and anti$\mathrm{HBC}$ as the primary tests. Anti-HBs is included for those with a history of vaccination or those who are anti-HBc positive, indicating natural infection in the past. This case would not have been discovered if testing were confined to looking for anti-HBs. It is

Table Hepatitis serology and AST results

\begin{tabular}{|c|c|c|c|c|c|c|c|}
\hline Date & $H B s A g$ & $\begin{array}{l}\text { Anti } H B c \\
\text { Total }\end{array}$ & $\underset{I g M}{A n t i} H B c$ & $H B e A g$ & Anti $H B e$ & Anti HBs & $\begin{array}{l}A S T \\
U / l\end{array}$ \\
\hline $\begin{array}{l}24.01 \cdot 91 \\
14.01 \cdot 92 \\
10.03 .92 \\
10.06 .92 \\
27.01 .93 \\
04.02 .93\end{array}$ & $\begin{array}{l}- \\
\overline{-} \\
\overline{-} \\
+ \\
-\end{array}$ & $\begin{array}{l}- \\
- \\
- \\
\overline{+} \\
+\end{array}$ & $\overline{+}$ & $\stackrel{+}{-}$ & - & $\begin{array}{l}0 \\
0 \\
14 \mathrm{miu} / \mathrm{ml} \\
0\end{array}$ & $\begin{array}{r}290 \\
91\end{array}$ \\
\hline
\end{tabular}

